\title{
Inheritance and the Dynamics of Party Identification
}

\author{
Martin Kroh • Peter Selb
}

\begin{abstract}
Extensive research efforts notwithstanding, scholars continue to disagree on the nature and meaning of party identification. Traditionalists conceive of partisanship as a largely affective attachment to a political party that emerges in childhood through parental influences and tends to persist throughout life. The revisionist conception of partisanship is that of a running tally of party utilities that is updated based on current party performance. We attempt to reconcile both schools of thought in an individual difference perspective, showing that the party loyalties acquired through parental influences confirm better the traditional view, while the attachments of individuals who did not inherit their parents' party loyalties exhibit features more closely matching the revisionist predictions. The analysis is facilitated by uniquely suited longitudinal household data emanating from the German Socio-Economic Panel Study that allow to study party identifications of young adults and their parents on an annual basis from 1984 to 2007 .
\end{abstract}

Keywords Party identification - State dependence - Trait dependence . Socialization - Germany - Dynamic panel model - Inheritance . Intergenerational transmission

\section{Kroh (ख)}

Socio-Economic Panel Study (SOEP), German Institute for Economic Research (DIW Berlin), Mohrenstr. 58, 10117 Berlin, Germany

e-mail: mkroh@diw,de

P. Selb

Department of Political Science and Management, University of Konstanz, Universitätsstr. 10, 78457 Konstanz, Germany

e-mail: Peter.Selb@uni-konstanz.de 


\section{Introduction}

Despite the centrality of party identification ${ }^{1}$ in studies of voting behavior and elections, scholars continue to disagree vehemently on its nature and meaning (for a recent overview, see the 2002 special issue of Political Behavior). Proponents of the traditional perspective conceptualize partisanship as a primarily affective attachment to a political party that develops at an early stage through parental influences, remains largely stable throughout life, is more or less immune to situational factors, and acts as an organizing principle for other political perceptions, attitudes, and behaviors (e.g., Campbell et al. 1960). Revisionists, on the other hand, conceive of party identification as an endogenous 'running tally' of party utilities that is constantly updated according to the positions of parties on different issues and personal evaluations of party performances (e.g., Fiorina 1981). Given that both notions yield dramatically different long-run predictions about important political features such as party system stability, the study of how real voters attach to parties is much more than just a devotional exercise.

The early stages of the debate have been characterized by a largely selective emphasis of either the origins-the traditionalist stronghold-or the dynamics of party identification-the 'natural' revisionists' domain. We will argue that valuable conceptual knowledge may be obtained from an integrated view of the origins and dynamics of party identification, since its origins might affect its dynamic behavior. In particular, we hypothesize that people who acquire their party identifications through pre-adult socialization will exhibit a relatively high level of persistence over time, as traditionalists would predict. On the other hand, those young adults who do not inherit their partisanships but form them independently of their parental background will be more responsive to later political experiences, which reflects the revisionist view. We will define persistence and responsiveness of party identification in terms of 'trait dependence' and 'state dependence' in a dynamic regression framework (Heckman and Borjas 1980). This elegantly reflects the essence of the traditional and the revisionist conceptions (Bartels et al. 2005; Shacher 2003), and allows us to empirically map voters onto a latent continuum ranging from a traditionalist to a revisionist pole.

Our research design is facilitated by longitudinal data, under-utilized by scholars of party identification: the German Socio-Economic Panel Study SOEP (see, Schmitt-Beck et al. 2006; Zuckerman 2005; Zuckerman et al. 2007). The household structure of this survey lends itself ideally for intergenerational studies and dyadic analyses in general; designs that are very popular in psychology (e.g., Eaves et al. 1999; Lake et al. 2000), economics (e.g., Björklund et al. 2002; Garces et al. 2002), and sociology (e.g., Duncan et al. 1998; Warren et al. 2002), but yet infrequently used in political science.

\footnotetext{
We follow common practice and use the terms party identification, partisanship, party affiliation, loyalty, attachment, and leanings interchangeably.
} 


\section{Origins of Partisanship}

Many of the early studies found that party identification originate at a stage of childhood before the ability to understand political issues and to evaluate party performance is fully developed (Easton and Dennis 1969; Greenstein 1965; Hess and Torney 1967), and that children frequently share their parents' party affiliations (Campbell et al. 1960; Levin 1961). These findings tentatively corroborate the traditional view, which conceives of partisanship as a primarily affective predisposition that is transmitted from parents to offspring via parental political socialization. Numerous qualifications have since been placed on the finding of strong parent-child congruencies in partisanship. For example, Jennings and Niemi $(1968,1981)$ showed that previous studies overrated the degree of similarity between parents and children due to projection effects in surveys of adolescents alone (see also Westholm 1999). However, the data they had collected independently from parents and offspring still revealed a substantial level of partisan congruency (e.g., Zuckerman et al. 2007). Moreover, Glass et al. (1986) have demonstrated that parental political orientations continue to contribute significantly to young adults' affiliations even if intergenerational persistence in socioeconomic status-a prominent rival explanation-is taken into account (see also Cassel 1982; Knoke and Hout 1974; Tedin 1974).

The revisionist view, on the other hand, offers virtually no independent account for the origins of party identification in young adults (Franklin 1984). However, most revisionist models provide an initial state term that allows for socialization influences, although its conceptual status remains rather vague (Achen 1992; Fiorina 1981; Franklin and Jackson 1983; Niemi and Jennings 1991). Only recently has Achen (2002) formally laid out the rational choice foundations of this term. Accordingly, children use their parents' party identifications as Bayesian 'prior beliefs' about their own party utilities, given that they are too inexperienced to judge how their own (yet unknown) social positions will relate to party benefits when they begin participating in political life. Thus, parent-child congruencies in partisanship do not necessarily invalidate the revisionist perspective.

\section{Partisanship Dynamics}

Early long-term panel studies argued that there is probably greater intra-individual volatility in party loyalties than the traditional conception would have one expect (Jennings and Niemi 1981). Moreover, corroborating the central claim of the revisionists, Fiorina (1981) has found that individuals change their attachments in response to performance evaluations, and several other studies have indicated that party identifications are adjusted to changing policy preferences (i.e., Franklin 1984; Franklin and Jackson 1983; Niemi and Jennings 1991). Proponents of the traditional conception have in turn attributed a substantial share of individual-level movement to measurement error in survey data (Dalton 1980; Green and Palmquist 1990, 1994), and have argued that there is simply not much variability left to be explained by changing political factors once measurement error is taken into account. 
However, validating the two conceptions of partisanship based on estimates of temporal stability is increasingly considered a problematic strategy. Far from claiming perfect stability over the lifetime, Campbell et al. (1960) already identified several factors that may trigger shifts in individual and aggregate partisanship. Conversely, Achen $(1992,2002)$ has formally demonstrated that stable partisanship may also emerge from a rational model of Bayesian assimilation of new information: the longer the series of evaluations of parties, the less responsive it is to new information. ${ }^{2}$ Previous research showing a decreasing responsiveness of political orientations by age may be considered indicative of this notion (Alwin et al. 1991).

Then again, Green and Yoon (2002) and Green et al. (2002) demonstrate that current political events may exert short-term influences on partisanship which, however, wear out over time, i.e., partisans tend to return quickly to their initial state. Revisionists again have doubted the consistency of these results, and have come to divergent conclusions with alternative estimators (Wawro 2002). Still others have offered an altemative interpretation of these findings: Parties adjust their policies and candidacies to counteract losses in support among their electorate, and as a result, former party followers who have left the ranks revise their evaluations and return (Fiorina 2002).

\section{An Integrated View of Origins and Dynamics}

Far from being exhaustive, the preceding sections have given at least a flavor of the course (and the dilemma) of the discussion between proponents of the traditional conception of partisanship and their revisionist counterparts. Both theoretical perspectives accommodate a vast range of initially conflicting empirical facts on partisanship. Volatility and even a certain extent of responsiveness to short-term political forces is seemingly as compatible with the traditional conception as is intergenerational transmission and persistence with the revisionist view. Also the use of innovative measurement instruments (Burden and Klofstad 2005; Greene 1999, 2004), experimental research designs (Cowden and McDermott 2000), and long-term panel surveys (e.g., Schmitt-Beck et al. 2006), has not helped to settle these issues.

Some authors have called for individual difference perspectives of the nature of partisanship (see Box-Steffensmeier and Smith 1998). Fiorina (1981) and Franklin (1984), for example, have suggested that party identifications may well have prepolitical origins in early childhood socialization, but that political evaluations are incorporated into partisanship later in life as young adults become more aware and informed about politics. Conversely, Marcus et al. (2000) have argued that the cumulative effect of repeated (and presumably rational) voting decisions over time may flow into emotional attachments to a particular party. Bartels et al. (2005) and Green and Yoon (2002) focus on inter-individual rather than intra-individual differences, hypothesizing that party identifications among voters with lower levels of political awareness and information will be less responsive to current political forces and thus correspond to the traditional view, while party identifications among

\footnotetext{
2 For a traditionalist critique of Achen's model, again, see Gerber and Green (1998),
} 
more sophisticated voters will correspond more to the revisionist view. While their own empirical findings have not confirmed this idea, Kroh and Selb (2009) provide first evidence of declining levels of partisan stability as a function of education and political interest.

We hypothesize that the circumstances under which partisanships are formed in young adults govern their dynamics in later life. This hypothesis is well grounded in the literature on party identification as well as the more general literature on political attitudes. In the traditional view, party identification is said to be a persistent political predisposition because it is pre-politically acquired early in life (Campbell et al. 1960). The intergenerational transmission of partisanship thus becomes a premise of the traditional view.

An often cited finding of early attitude research is that attitudes systematically differ in their stability (Converse 1964; Converse and Markus 1979). Sears and his colleagues $(1980,1983)$ associate these differences with the object of attitudes and posit a hierarchy of so-called symbolic versus non-symbolic attitudes ranging from party identification, ideological orientations and attitudes towards social groups to political efficacy and trust in government. Corroborating this view, Jennings and Niemi (1968) and Niemi et al. (1978) have shown that with partisanship, parentchild similarities are stronger than with other, less symbolic political attitudes (Sears et al. 1980; Sears and Funk 1999). Krosnick (1991) in his critical reappraisal of previous evidence, however, concludes "that focussing on the attitude object may not be the most effective way to distinguish strong attitudes from weak ones. Any given political attitude is likely to be strong among some individuals and weak among others". Applying this notion to the analysis of partisanship, we expect that in some individuals, partisanship is a symbolic orientation, while for others, partisanship is non-symbolic.

But what makes partisanship a symbolic attitude in some individuals but not in others? According to Sears (1983), symbolic attitudes differ from non-symbolic attitudes in that they are acquired early in life, primarily through parental conditioning, while non-symbolic attitudes are formed later in life through information integration (see Bandura 1973; Searing et al. 1976). As a result, symbolic attitudes contain a strong affective component and are more resistant to incoming information. Non-symbolic attitudes, on the other hand, contain a strong cognitive component and are more responsive to new pieces of deviating information. Thus, partisanship should be symbolic in character in individuals who have acquired their partisanship at an early stage through parental imprinting and largely non-symbolic in those individuals who have acquired their partisanship through influences outside their parents' home.

Following this line of reasoning, we propose an individual difference perspective in the dynamics of party identification that stresses the importance of parental imprinting. We hypothesize that those individuals who have inherited their parents' party loyalties will exhibit a relatively high level of persistence in their partisanship. In contrast, young adults who have not inherited their parents' party loyalties but formed them independently-either because they grew up with parents who were politically indifferent or they were in conflict with their parents' partisanship-will exhibit a relatively high propensity to constantly update their party identification. 


\section{Data}

Investigating both the origins and the dynamics of partisanship in one model puts high demands on the empirical data. The analysis necessitates measures of individuals' preadult political environment, i.e., information on the political views of individuals' parents when they themselves were in their formative years. Moreover, to draw conclusions about the consequences of the effects of parental socialization for the dynamics of party identifications in later life, the analysis requires a continuous, long-term coverage of respondents' political views as adults. The German Socio-Economic Panel Study (SOEP) is one of the few data sets that meets both requirements. By surveying all the members of a large, representative sample of German households, SOEP enables us to focus on the experiences of young adults even before they reach voting age. The ongoing annual panel study currently covers 25 years, a time span that also permits us to analyze the long-term dynamics in partisanship. ${ }^{3}$

But how about the suitability of a European country to our endeavor? Some observers claim that party identification is not a meaningful concept outside the United States. For instance, social groups and ideological orientations are said to be more salient in some European countries than parties (e.g., Fleury and Lewis-Beck 1993; Shively 1972). Other scholars doubt that party identification in Europe is any distinct from party choice in elections (e.g., Butler and Stokes 1969; Thomassen 1976). Yet, for Germany, evidence from numerous studies confirm the validity of party identification in terms of its interrelation with other political concepts, its stability, and its distinctiveness from actual party choice (for a review see Falter et al. 2000; Zuckerman 2005). Of course, the "traveling capacity" (Schmitt- Beck et al. 2006) of the American standard instruments to measure partisanship is limited to twoparty systems. SOEP like most other German surveys measures partisanship by two questions, a protocol that repeats the set of questions in each and every one of SOEP's waves. The English language translation of the relevant questions reads: "Many people in Germany are inclined toward a certain political party, although from time to time they vote for a different political party. What about you: Are you inclinedgenerally speaking-toward a particular party?" Those who respond 'Yes' are then asked, "Toward which one?". The response defines their specific partisanship. Those who say 'No' to the first question we categorize as having no party inclination. ${ }^{4}$

We consider the first partisanship reported by young adults at age 17-19 to represent their initial partisanship. If a person has not chosen a party at that age but

\footnotetext{
${ }^{3}$ Currently, SOEP surveys 24,000 individuals in 12,000 households. The data set consists of seven subsamples, drawn from the population living in Germany at different points in time, in order to compensate for panel attrition and to allow for group-specific analyses (Kroh and Spiess 2008).

4 The difference in question formats leads to higher rates of independents in European surveys as compared to US data. In a cross-sectional perspective, almost $40 \%$ of the SOEP sample reported in the 1980 s not to support any party, today this figure hovers around $50 \%$, However, taking a longitudinal perspective. we find that almost $90 \%$ of the sample in the $1980 \mathrm{~s}$ name at least once a party in a five-year period and today this still holds for more than $70 \%$ of the sample. We therefore conclude a high prevalence of partisanships in Germany despite the inflated cross-sectional rates of independents.
} 
remains undecided, we will consider this person to have an indifferent initial party identification and remove the respondent from the analysis. ${ }^{5}$

If parents' reported party inclinations during their offspring's childhood and youth clearly favor one party, i.e., if the sum of statements supportive to a party exceeds the sum of all reports supportive to other parties, we consider the parental political socialization to be leaning towards that party. ${ }^{6}$ If parents never name a party or if there is no absolute majority of statements in favor of one party, we consider the socializing experience of young adults to be indifferent. This measure based on the unweighted sums of parents' party statements is designed to capture the general political color of parental households or the partisan background. ${ }^{7}$

Successful transmission of party identifications is defined as a match between partisan background and young adults' initial partisanship at age 17, 18, and 19. To be sure, there are other reasons besides early learning why children may identify with the same parties as their parents do or did, in particular, similar social status (but, McAllister and Kelley 1985; Glass et al. 1986). Therefore, our inheritance measure solely separates those young adults who have potentially acquired their party identifications through preadult socialization from those who more or less certainly did not. However, more direct measures of successful parental rolemodeling are not readily available, and this one ensures that if we err, we will at least err on the conservative side, since it tends to blur the distinctions between both groups of young adults.

As reported elsewhere (Kroh and Selb 2009), we find strong evidence for the successful transmission of party identifications: For a young adult from a socialdemocratic family, for instance, the odds of becoming identifier of the SPD herself at age $17-19$ are 14 times as large than if she came from a christian-democratic family. Of the overall 2,552 respondents in the SOEP for whom we observe sufficient information on their partisan background and who ever report a party identification themselves, 1,583 indicated an initial party identification for one of

\footnotetext{
5 As reported in the review of the socialization literature, several studies suggest that the transmission of party identifications may even start at a time when young children themselves lack a basic understanding of political processes and events (e.g., Greenstein 1965). Other authors, however, date the formation of an initial party identification as late as in the mid-20s (Alwin et al. 1991; Jennings and Niemi 1981; Jennings and Markus 1984). Due to these ambiguities, many scholars use the first vote as crystallization of the initial political preferences (Campbell et al. 1960; Hyman 1959). For a critical review, see Sears and Valentino (1997). We therefore employ a very broad definition of the formative years, considering parents' partisanship during their offspring's entire childhood. We define the age of 17 as terminating this period of parental primacy and beginning a second period in which young adults potentially start incorporating externally available political information.

${ }^{6}$ At a maximum level, we observe the partisanship of both mother and father in these 17 years. At a minimum level, we consider at least 2 years of information on (single) parents' party identification as sufficient to define the socializing experience of young adults.

7 Based on the available partisan statements of parents, other procedures for building a compound measure of the political color of parental households can be used. For instance, one could weight recent statements more heavily in the construction of such a measure than parents" partisanship 15 years before. We refrain from such an approach as our measure of parental partisanship is not primarily meant to maximize the prediction of young adults' initial partisanship but is designed to also capture the steady partisan cues provided by parents during their offspring's childhood that may plausibly affect the persistence of young adults partisanship.
} 
the five major German parties, the Social-Democrats (SPD), the ChristianDemocrats (CDU/CSU), the Liberals (FDP), the Greens (Alliance90/The Greens), and the Socialists (PDS) at age 17-19. These respondents constitute our sample. Of these, 912 respondents $(58 \%)$ inherited their parents' partisanship. The other 671 either came from an independent household or initially identified with a party other than their parents. ${ }^{8}$

\section{Modeling Partisanship Dynamics}

In recent years, some scholars have adapted the concepts of 'trait' and 'state dependence' from labor market economics (see Hsiao 2003) to the modeling of partisanship dynamics (Green and Yoon 2002; Wawro 2002; Bartels et al. 2005).

Trait dependence as related to party identification depicts a time-invariant inclination or latency of an individual to support a certain party. While a strong latency as so defined does not imply that individuals will never desert their party, it nevertheless means that if they desert, they will quickly return to their original partisan predisposition or 'trait'. Trait dependence thus closely resembles the traditional notion of partisanship. State dependence, on the other hand, suggests that individuals continuously adjust their party identifications based on recent events, and thus neatly captures the concept of responsive partisanship (Fiorina 1981). As opposed to trait-dependent party loyalties, state-dependent partisan orientations are solely an update of the partisan orientations of the previous period.

Of course, individual partisan orientations may be both trait and state dependent to some extent. Figure 1 illustrates the empirical consequences for the dynamics of partisanship when voters are located on different positions on a latent continuum ranging from a traditionalist to a revisionist pole. At the traditionalist pole, current party identification is trait dependent, i.e., strictly a function of an individual's timeinvariant latency to support this party. At the revisionist pole, the current level of partisanship is just an update of its previous state, that is, purely state dependent. In between these extremes, party identification may be both trait and state dependent to a certain extent. ${ }^{9}$ To illustrate, suppose that some voters initially, at $t=0$, have an arbitrary level of partisan leaning of 0.75 . In the following period at $t=1$, the attractiveness of that party is sharply reduced, for instance, due to a political scandal or a temporal change of leadership, and their level of partisanship drops to 0.25 .

The difference between trait and state dependent voters emerges after the temporal shock. The darkest line in Fig. 1 illustrates an extreme case where party

\footnotetext{
${ }^{8}$ Although the SOEP on principle is a random sample of the population living in Germany, the analyzed sample in the present analysis is not representative of the general population at a single point in time but of the cohorts borm between 1969 and 1989. For the first cohort of 1969, for instance, we obtain the minimum of two observations on parental partisanship in the waves 1984 and 1985 when respondents thernselves are 15 and 16 years old. The initial partisanship of the 1969 cohot is then measured in the subsequent waves 1986,1987 , or 1988 at age 17,18 , or 19. However, our sample is selective in that it only contains individuals for whom we also have sufficient information on their parents.

${ }^{9}$ If both state and trait dependence were governing individual party identification, the term true state dependence would be used to denote the effect of a recent (change in a) party leaning on present partisanship, controlling for trait dependence.
} 
identification is purely trait dependent, i.e., voters behave fully in line with the traditional view. Here the chance of supporting that party immediately returns to the initial level of 0.75 at $t=2$. At the opposite extreme, where party identification is purely state dependent (the lightest line), i.e., voters behave in line with the revisionist view, the chance of supporting the party will permanently remain at the level of 0.25 . The remaining three intermediate scenarios illustrate situations where party identification is driven both by state and trait dependence, although at different ratios of mixture. Clearly, the more trait relative to state dependent a party identification is, the shorter the period required to return to the initial level after a temporal shock and vice versa.

Of course, this heuristic model is simplistic in that there is more than a single party as well as partisan independence to consider. In the empirical application, we therefore model present party attachments for the SPD, the CDU/CSU, the FDP, the Greens, and the Socialists in a multinomial logit framework (Alvarez and Nagler 1998) as a function of partisanship in the previous period. The panel structure of our data allows us to estimate the party-specific trait dependence parameters from the correlation of the residual variance across these repeated observations of an individual. We also allow the residual terms to be correlated across the different parties to account for similarities between them (for a detailed discussion of the random effects multinomial logistic regression model, see Hsiao 2003; Skrondal and Rabe-Hesketh 2003).

A caveat must be placed on the estimation of the state and trait dependence parameters by way of such a dynamic random effects multinomial logit model: If we expect current party identification to be trait dependent, the lagged dependent variable would also be a function of this time-invariant trait and thus the respective estimate of state dependence parameter would be plagued by endogeneity bias. A solution to this problem is the introduction of the common source of both, i.e., the initial status of the dependent variable (Wooldridge 2002). In our case, this initial condition is the party identification of a person measured at the age of 17-19. But note that the introduction of the time-invariant initial party identification detracts

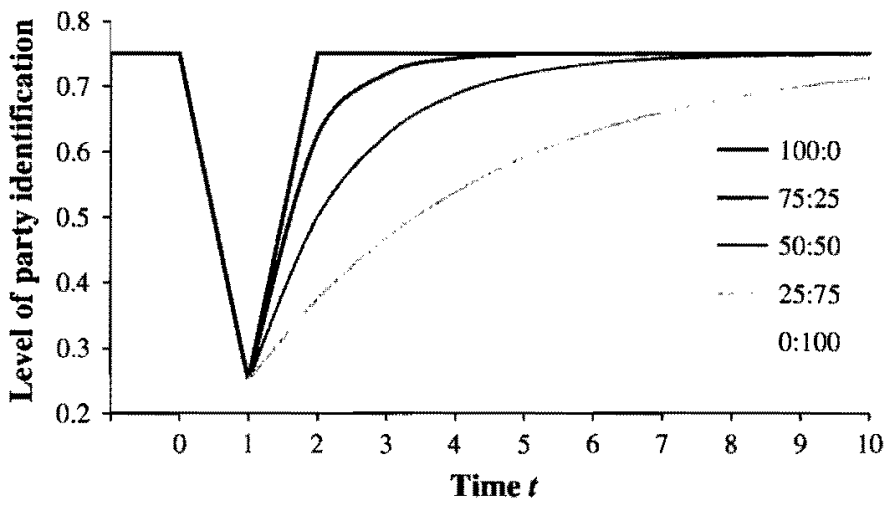

Fig. 1 Adjustment of individual party identifications after a temporary shock at time $t=1$ by different mixtures of trait relative to state dependence 
from the estimates of the trait dependence parameters that is based on the residual commonality of partisanship in repeated observations. Conceptually, however, both reflect the trait dependence of party identifications: while the effect of the party identification at age 17-19 captures the observed trait dependence attributable to the initial condition, the remaining correlation in partisanship within individuals represents their unobserved trait dependence.

\section{Results}

Tables 1 and 2 present the real-world estimates of true state dependence and trait dependence, of party identification described before. For reason of clarity, we report the observed state and trait dependence of partisanship and the estimated residual unobserved trait dependence in two separate tables.

The first column of Table 1 lists estimates of the effect of the lagged party identification and the initial party identification for those individuals who, as young adults, either indicated another party identification than that of their parents or come from politically indifferent households. ${ }^{10}$ The second column lists estimates for those who have inherited their party identifications from their parents. The third column reports the differences between the parameter estimates in both groups. The test statistics pertaining to the third column are derived from $\chi^{2}$-difference tests.

In both the inheritance and the non-inheritance group, initial PID and lagged PID significantly affect current partisanship. Both groups of young adults thus displays dynamic features of party identification that can be interpreted as a mixture of the traditional and the revisionist view. The $\chi^{2}$ difference tests reported in the last column suggest, however, that the ratios of ingredients differ between the two groups.

In line with our expectation that the trait dependence of partisanship is particularly prevalent in the inheritance-group, we find a stronger effect of the initial party identification on current party identification (4.39) than in the group of respondents who did not inherit their initial party identification $(2,17)$. This finding supports our prediction that the inheritance group exhibits a higher tendency to quickly return to their initial partisanship after a temporal shock. Complementarily, the state dependence parameters indicate that previous states in party affiliation more strongly affect present statements of party loyalty in the non-inheritance group as opposed to the inheritance-group (these differences are significant at $p<.01$ ). This finding supports our prediction that updates or revisions of the most recent state of partisanship leave deeper imprints in the partisan history of those who have not inherited their attachments from their parents. Again, the results indicate that the differences between the two groups are a matter of degree rather than deterministic.

\footnotetext{
${ }_{10}$ Note that we restrict our sample to those adolescents who do report an initial party identification at age 17-19 and ignore respondents who remain indifferent. Young adults from indifferent settings as well as those from partisan households who did not take up their parents views are highly similar in terms of the dynamic behavior of their party identifications and subsequent analyses. We therefore treat these two groups jointly as representing non-inherited party identifications.
} 
Table 1 True state and observed trait dependence in party identification by inheritance status. Estimates from the dynamic random effects multinomial logit model

\begin{tabular}{lrrr}
\hline Partisanship & Non-inherited & \multicolumn{1}{c}{ Inherited } & \multicolumn{1}{c}{ Difference } \\
\hline Initial PID & $2.170(.157)^{* * *}$ & $4.390(.178)^{* * * *}$ & $-2.220(.213)^{* * *}$ \\
Lagged PID & $.874(.051)^{* * *}$ & $.686(.042)^{* * *}$ & $.188(.064)^{* * *}$ \\
Intercepts & & & \\
$\quad$ SPD & $-2.503(.159)^{* * *}$ & $-4.485(.189)^{* * * *}$ & $1.987(.215)^{* * *}$ \\
CDU/CSU & $-3.212(.174)^{* * *}$ & $-3.927(.173)^{* * *}$ & $.715(.211)^{* * *}$ \\
FDP & $-4.809(.324)^{* * *}$ & $-4.953(.310)^{* * *}$ & $.145(.313)$ \\
$\quad$ Green & $-3.511(.199)^{* * *}$ & $-4.197(.224)^{* * *}$ & $.686(.235)^{* * *}$ \\
PDS & $-4.989(.369)^{* * *}$ & $-5.538(.432)^{* * *}$ & $.550(.333)^{*}$ \\
\hline
\end{tabular}

Note: Entries of the last column pertain to $\chi^{2}$ difference tests. ${ }^{* * *} p<.01 ;{ }^{* *} p<.05 ; * p<.10$. Modeling the effect of the initial and lagged partisanship in current partisanship requires at least three observations on each individual which restricts the the total number of observations to be included in the analysis to $N=1,375$. Data Source. SOEP 1984-2007

Table 2 Variances and covariances of unobserved trait dependence in party identifications. Estimates from the dynamic random effects multinomial logit model

\begin{tabular}{llllll}
\hline & SPD & CDU/CSU & FDP & Green & PDS \\
\hline SPD & $3.727(.397)^{* * *}$ & & & & \\
CDU/CSU & $-.484(.298)$ & $3.243(.358)^{* * *}$ & & & \\
FDP & $-.831(.434)^{*}$ & $1.034(.383)^{* *}$ & $4.853(.896)^{* * *}$ & & \\
Green & $1.783(.399)^{* * *}$ & $-.156(.411)$ & $.725(.476)^{*}$ & $5.912(.874)^{* * *}$ & \\
PDS & $1.278(.694)^{*}$ & $.552(.609)$ & $-.912(.672)$ & $2.333(.710)^{* * *}$ & $5.067(1.035)^{* * * *}$ \\
\hline
\end{tabular}

Note: Reference category is indifference. ${ }^{* * *} p<.01 ; * * p<.05 ; * p<.10$. Data Source. SOEP, 1984 2007

Table 1 also reports party specific intercepts relative to the reference category of our model, which is political indifference. The negative estimates indicate that political indifference is the most common of all choices, even among those individuals who initially identified with a party. Note that the smaller estimates in the non-inheritance group is a consequence of controlling for the state of partisanship in the previous period and not a consequence of a per se lower rate of indifference. Respondents who agreed with their parents on a party identification are in general more likely to report a partisanship. However, this difference is already captured in the effect of previous partisanship. "I

Table 2 summarizes the estimates of the random effects of our panel regression model, i.e., the residual unobserved trait dependence for each party and the covariances between them. For the interpretation of the parameters, note that these

\footnotetext{
II We have also fitted a baseline model that omits the lagged and the initial party identification. The estimates suggest, in contrast to the findings of Table 1, that, on average, the inheritance group is less likely to report political indifference.
} 


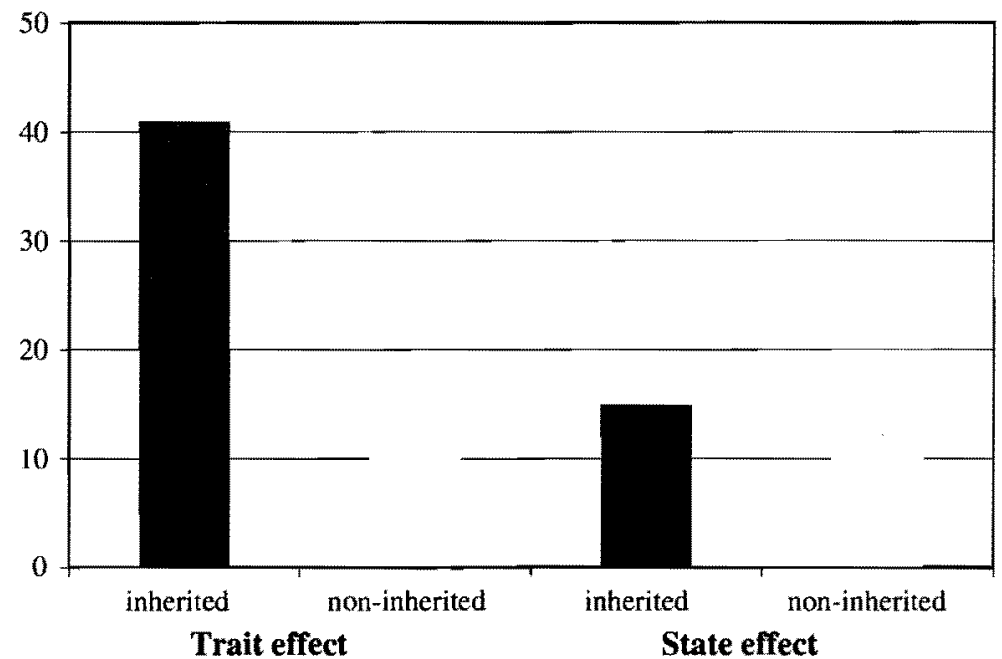

Fig. 2 Marginal effect of the lagged and initial party identification on supporting a party at present by inheritance status. Predicted probabilities are based on the estimates of Tables 1 and 2

are conditional on the estimates of lagged and initial partisanship. Only the combination of the observed as well as the unobserved time-invariant latency is informative about the levels of trait dependence of his or her party loyalty.

The off-diagonal parameters suggest that the initial party identification does not capture all the trait dependence in later reports of party identifications. In other words, a considerable fraction of the stability of individual partisanship emerges after the acquisition of an initial party identification. This seems to hold particularly for the smaller parties as, for instance, the Greens (5.912). Our model also allows for covariation between the latent support for different parties. Not surprisingly, we find that, for instance, the individual-specific latency for the Greens is positively correlated with support for the habitual coalition partner, the SPD $(r=1.783$ / $(\sqrt{3.727} \times \sqrt{5.912})=.380)$. The same holds for the CDU/CSU and the FDP, again, habitual coalition partners in the German political system $(r=.258)$.

In sum, the results suggest a generally stronger tendency of individuals who inherited their parents' political views to retum to their initial equilibrium level of partisanship and a stronger tendency of individuals who did not inherit their parents' political views to update their partisanship in later life. Figure 2 displays marginal effects and thus provides a more intuitive idea of the substantive consequences of state and trait dependence by the inheritance status. The first two bars pertain to the observed trait dependence of partisanship while the last two bars pertain to the state dependence of partisanship.

Obviously, while the marginal trait effect is much stronger than the marginal state effect in the inheritance group ( 41 versus 15 percentage points), both marginal trait and state effect have about the same magnitude in the non-inheritance group (17 and 20 percentage points). 


\section{Discussion}

Our review of the ongoing debate over the conceptual status of party identification suggested that both rivaling conceptions, the traditional and the revisionist view, are empirically true to some extent. The aim of this paper was to reconcile the two conceptions and their distinct emphases on the origins and the dynamics of party identification in one individual difference perspective. More specifically, we hypothesized that party loyalties of young adults who inherited their political orientations from their parents will be more resistant to durable change than those emanating from other sources. The latter, on the other hand, will exhibit to a greater extent the features that have been claimed to be constitutive of party identification by the revisionist school of thought: short-term changes will have longer-lasting effects on partisanship. Our thesis is founded in the extensive socialization literature that argues that attitudes and values transmitted from parents to children become particularly central and affective-and thus more durable-concepts in an individuals world view. Attitudes and values learned independently from parents, on the other hand, are more susceptible to change. The empirical analyses supported our expectations.

Having said this, some qualifications are due. First, our empirical analysis was limited to voters who actually had developed an initial party identification at age 17-19. Likewise-even though we were taking advantage of an exceptional data source-we were able to follow up on young adults' partisan development until their late $30 \mathrm{~s}$ at longest. Therefore, generalizations for partisanship dynamics later in life and for the dynamics of partisan independence are unwarranted.

Second, we divided young voters in inheritance and non-inheritance groups in a rather crude manner. While this classification most likely yielded conservative estimates of group differences in partisanship dynamics, we also tended to overlook a potential 'sleeper effect', i.e., that apolitical young adults might drift towards their parents' partisanship later in life. ${ }^{12}$ Indeed, some additional analyses showed that in the non-inheritance group, parental partisanship exerted a robust effect on current party identification even after controlling for lagged and initial partisanship. In other words, if individuals who did not initially adopt their parents" partisanship changed their own party affiliation over time, they would often do so in the direction of their parents' political views. However, this effect did not change the higher state and lower trait dependence of partisanship in the non-inheritance as opposed to the inheritance group.

What may, in the end, be raised as an objection to advocates of both conceptions of party identification-at least as they are often presented in the literature - that their claim of the general validity of their respective conceptions. Our findings indicate that parental socialization is an important starting point for young adults' partisan histories, but by far not the only one. While traditionalists occasionally seem to overstate the role of parental socialization as exclusively determining initial party identifications, revisionists still appear to underestimate the long-lasting consequences of pre-adult socialization, not only for the initial state of party

\footnotetext{
12 Thanks to an anonymous reviewer for pointing to this.
} 
identification, but also for the dynamics of partisanship in later life. Hence, a stronger focus on the differential origins of party identification, in our view, would be highly informative, also for scholars interested in the dynamics of party identification.

\section{References}

Achen, C. H. (1992). Social psychology, demographic variables, and linear regression: Breaking the iron triangle in voting research. Political Behaviour, 14, 195-211.

Achen, C. H. (2002). Parental socialization and rational party identification. Political Behavior, 24, $151-169$.

Alvarez, R. M., \& Nagler, J. (1998). When politics and models collide: Estimating models of multiparty elections. American Journal of Political Science, 42, 55-96.

Alwin, D. F., Cohen, R. L., \& Newcomb, T. M. (1991). Political attitudes over the life span: The Bennington women after fffy years. Madison: University of Wisconsin Press.

Bandura, A. (1973). Social learning theory of identificatory processes. In D. A. Goslin (Ed.), Handbook of socialization theory and research. Chicago: Rand $\mathrm{McNally.}$

Bartels, B. L. Box-Steffensmeier, J. M., Smidt, C. D., \& Smith, R. M. (2005), Heterogeneity, statedependence, and the dynamics of individual-level party identification (Manuscript).

Björklund, A., Eriksson, T, Jäntti, M., Oddbjörn, R., \& Österbacka, E. (2002). Brother correlations in Denmark, Finland, Norway and Sweden compared to the United States. Journal of Population Economics, 15, 757-772.

Box-Steffensmeier, J. M., \& Smith, R. M. (1998). Investigating political dynamics using fractional integration methods. American Journal of Political Science, 42, 661-689.

Burden, B. C., \& Klofstad, C. A. (2005). Affect and cognition in party identification. Political Psychology, 26, 869-886.

Butler, D., \& Stokes, D. E. (1969). Poltitcal change in Britain. London: Macmillan.

Campbell, A., Converse, P. E., Miller, W. E., \& Stokes, D. E. (1960). The American voter. New York: Wiley.

Cassel, C. A. (1982). Predicting party identification: Who are the Republicans and who are the Democrats? Political Behavior, 4, 265-282.

Converse, P. E. (1964). The nature of belief systems in mass publics. In D. E. Apter (Ed.), ldeology and discontent (pp. 206-261). New York: Free Press.

Converse, P. E., \& Markus, G. B. (1979). Plus ca change ...: The New CPS Election Study Panel. American Political Science Review, 73, 32-49.

Cowden, J. A., \& McDermott, R. M. (2000). Short-term forces and partisanship. Political Behavior, 22, 197-221.

Dalton, R. J. (1980). Reassessing political socialization: Indicator unreliability versus generational transfer, American Political Science Review, 74, 421-431.

Duncan, G. J., Yeung, W. J., Brooks-Gunn, J., \& Smith, J. R. (1998). How much does childhood poverty affect the life chances of children? American Sociological Review, 63, 406-423,

Easton, D., \& Dennis, J. (1969). Children in the political system. Ney York: McGraw-Hill.

Eaves, L., Heath, A., Martin, N., Maes, H., Neale, M., Kendler, K., Kirk, K., \& Corey, L. (1999). Comparing the biological and cultural inheritance of personality and social attitudes in the Virginia 30000 study of twins and their relatives. Twin Research, $2,62-80$.

Falter, J., Schoen, H., \& Caballero, C. (2000). Dreissig Jahre danach. Zur Validierung des Konzepts 'Parteildentifikation' in der Bundesrepublik. In M. Kleín, W. Jagodzinski, E. Mochmann, \& D. Ohr (Eds.), 50 Jahre Empirische Wahlforschung in Deutschland. Entwicklungen, Befunde, Perspektive, Daten. Wiesbaden; Westdeutscher Verlag.

Fiorina, M. P. (1981). Retrospective voting in American National Elections. New Haven, CT: Yale University Press.

Fiorina, M. P. (2002). Parties and partisanship: A 40-year retrospective, Political Behavior, 24, 93-115.

Fleury, C. J., \& Lewis-Beck, M. S. (1993). Anchoring the French voter: Ideology versus party. Journal of Politics, 55, 1100-1109. 
Franklin, C. H. (1984). Issue preferences, socialization, and the evolution of party identification. American Journal of Political Science, 28, 459-478.

Franklin, C. H., \& Jackson, J. E. (1983). The dynamics of party identification. American Political Science Review, 77, 957-973.

Garces, E., Thomas, D., \& Currie, J. (2002). Longer-term effects of head start. American Economic Review, 92, 999-1012.

Gerber, A., \& Green, D. P. (1998). Rational leaming and partisan attitudes. American Journal of Political Science, 42, 794-818.

Glass, J., Bengtson, V. L., \& Dunham, C. C. (1986). Attitude similarity in three-generation families: Socialization, status inheritance, or reciprocal influence? American Sociological Review, 51, 685-698.

Green, D, P, \& Palmquist, B, (1990). Of artifacts and partisan instability. American Journal of Political Science, 3, 872-902.

Green, D. P., \& Palmquist, B. (1994). How stable is party identification? Political Behavior, 16, 437-466.

Green, D. P., Palmquist, B., \& Schickler, E. (2002). Partisan hearts and minds. Political parties and the social identities of voters. New Haven/London: Yale University Press.

Green, D. P., \& Yoon, D. H. (2002), Reconciling individual and aggregate evidence concerning partisan stability: Applying time-series models to panel data. Political Analysis, 10, 1-24.

Greene, S. (1999). Understanding party identification: A social identity approach. Political Psychology, $20,393-403$.

Greene, S. (2004). Social identitiy theory and party identification. Social Science Quarterly, 85, 136-152.

Greenstein, F. I. (1965). Children and politics, New Haven: Yale University Press.

Heckman, J. J., \& Borjas, G. J. (1980). Does unemployment cause future unemployment? Definitions. questions and answers from a continuous time model of heterogeneity and state dependence. Economica, 47, 247-283.

Hess, R. D., \& Torney, J. D. (1967). The development of political attitudes in children. Chicago: Aldine.

Hsiao, C. (2003). Analysis of panel data. Cambridge: Cambridge University Press.

Hyman, H. H. (1959). Political socialization. Glençoe: Free Press.

Jennings, M. K., \& Markus, G. B. (1984). Partisan orientations over the long haul: Results from the threewave political socialization panel study. The American Political Science Review, 78, 1000-1018.

Jennings, M. K., \& Niemi, R. G. (1968). The transmission of political values from parent to child. The American Political Science Review, 62, 169-184.

Jennings, M. K., \& Niemi, R. G. (1981). Generations and politics. Princeton: Princeton University Press.

Knoke, D., \& Hout, M. (1974). Social and demographic factors in American political party affiliations, 1952-72. American Sociological Review, 39, 700-713.

Kroh, M., \& Selb, P. (2009). Individual and contextual origins of durable partisanship. In J. Bartle \& P. Bellucei (Eds.), Political parties and partisanship: Social identity and individual attitudes (pp. 107-120). London: Routledge.

Kroh, M., \& Spiess, M. (2008). Documentation of sample sizes and panel attrition in the German Socio Economic Panel (SOEP) 1984-2007. Number 39 in Data Documentation. Berlin: DIW.

Krosnick, J. A. (1991). The stability of political preferences: Comparisons of symbolic and nonsymbolic attitudes. American Journal of Political Science, 35, 547-576.

Lake, R. I., Eaves, L. J., Maes, H. H., Heath, A. C. \& Martin, N. G. (2000). Further evidence against the environmental transmission of individual differences in neuroticism from a collaborative study of 45,850 twins and relatives on two continents. Behavior Genetics, 30, 223-233.

Levin, M. B. (1961). Social climates and political socialization. Public Opinion Quarterly, 25, 596-606.

Marcus, G. E., Neuman, W. R., \& McKuen, M. (2000). Affective intelligence and political judgment. ChicagolLondon: University of Chicago Press.

McAllister, I., \& Kelley, J. (1985). Party identification and political socialization: A note on Australia and Britain. European Journal of Political Research, 13,111-118.

Niemi, R. G., \& Jennings, M. K. (1991). Issues and inheritance in the formation of party identification. American Journal of Political Science, 35, 970-988.

Niemi, R. G., Ross, R. D., \& Alexander, J. (1978). The similarity of political values of parents and college-age youths. Public Opinion Quarterly, 42, 503-552.

Schmitt-Beck, R., Weick, S., \& Christoph, B. (2006). Shaky attachments: Individual-level stability and change of partisanship among west German voters, 1984-2001. European Journal of Political Research, 45, 581-602.

Searing, D., Wright, G., \& Rabinowitz, G. (1976). The primacy principle: Attitude change and political socialization. British Journal of Political Sclence, 6, 83-113. 
Sears, D. O. (1983). The persistence of early political predispositions: The role of attitude object and lie stage. In W. Wheeler \& P. Shaver (Eds.), Review of personality and social psychology (pp. 79-116). Beverly Hills: Sage.

Sears, D. O., \& Funk, C. L. (1999). Evidence of long-term persistence of adults' political predisposition. Journal of Politics, $61,1-28$.

Sears, D. O., Lau, R. R., Tyler, T. R., \& Allen, H. M. (1980). Self-interest vs. symbolic politics in policy attitudes and presidential voting. American Political Science Review, 74, 670-684.

Sears, D. O., \& Valentino, N. A. (1997). Politics matters: Political events as catalysts for preadult socialization. American Political Science Review, 91, 45-65.

Shachar, R. (2003). Party loyalty as habit formation. Journal of Applied Econometrics, 18, 251-269.

Shively, W. P. (1972). Party identification, party choice, and voting stability: The Weimar case. American Political Science Review, 66, 1203-1225.

Skrondal, A., \& Rabe-Hesketh, S. (2003). Multilevel logistic regression for polytomous data and rankings. Psychometrika, 68, 267-287.

Tedin, K. L. (1974). The influence of parents on the political attitudes of adolescents. American Political Science Review, 68, 1579-1592.

Thomassen, J. (1976). Party identification as a cross-national concept: It's meaning in the Netherlands. In C. Ivor, B. Ian, \& D. Farlie (Eds.), Party identification and beyond. Representations of voting and party competition (pp. 63-79), London: Wiley.

Warren, J. R., Sheridan, J. T., \& Hauser, R. M. (2002). Occupational stratification across the life course: Evidence from the Wisconsin longitudinal study. American Sociological Review, 67, 432-455,

Wawro, G. (2002). Estimating dynamic panel data models in political science. Political Analysis, 10, $25-48$.

Westholm, A. (1999). The perceptual pathway: Tracing the mechanisms of political value transfer across generations. Political Psychology, 20, 525-551.

Wooldridge, J. M. (2002). Econometric analysis of cross-section and panel data. Cambridge: MIT Press.

Zuckerman, A. S. (Ed.). (2005). The social logic of partisanship. Philadelphia: Temple.

Zuckerman, A. S., Dasovic, J., \& Fitzgerald, J. (2007). Partisan families: The social logic of bounded partisanship in Germany and Britain. Cambridge: Cambridge University Press. 